\title{
Possible Antibacterial Activity of Curcumin and Mangiferin in Patients with Helicobacter pylori-Associated Functional Dyspepsia
}

\author{
Ahmed M Ali* \\ Department of Clinical Pharmacy, October 6 University, Egypt
}

Submission: May 04, 2020; Published: May 19, 2020

*Corresponding author: Ahmed M Ali, Department of Clinical Pharmacy, Faculty of Pharmacy, October 6 University, October 6 City Central Axis, Area 1/1, Giza Governate, Egypt

\begin{abstract}
Background and objectives: Since the introduction to the scientific community by Marshall and Warren in 1982, the gram-negative bacterium Helicobacter pylori (H. pylori or HP), is now recognized as the primary causative agent associated with the development of gastritis and peptic ulcer disease. The effectiveness of many of the frequently recommended antibiotic-based $H$. pylori eradication regimens has been increasingly compromised by antimicrobial resistance and the higher incidence of adverse effects. Some in vitro studies have shown the effectiveness of curcumin and mangiferin against Helicobacter pylori. The aim of this study is to test the efficacy of curcumin and mangiferin as components of dual or triple proton pump inhibitor-based H. pylori eradication regimens in patients with $H$. pylori-associated functional dyspepsia.
\end{abstract}

Methods: H. pylori status was tested using the non-invasive stool antigen test before and 4 weeks after eradication therapy.

Results: Following 14-day therapy, significantly higher eradication rates were obtained with triple curcumin/mangiferin/omeprazole regimen compared to dual curcumin/omeprazole and dual mangiferin/omeprazole regimens ( $90 \%$ versus $60 \%$ and $50 \%, p \leq 0.05$ ). All eradication regimens dramatically reduced dyspeptic symptoms and were well tolerated with negligible side effects.

Conclusions: Curcumin and mangiferin preparations traditionally used for the treatment of gastrointestinal disorders are effective as components of $H$. pylori eradication regimens with little or no adverse reactions.

Keywords: Helicobacter pylori; Curcumin; Mangiferin; Omeprazole; Functional dyspepsia

Abbreviations: GI: Gastrointestinal; MALT: Mucosa-Associated Lymphoid Tissue; GORD: Gastro-Oesophageal Reflux Disease; IBS: Irritable Bowel Syndrome; HpSA: Helicobacter Pylori Stool Antigen; ADRs: Adverse Drug Reactions

\section{Introduction}

Helicobacter pylori (H.pylori) is a gastric Gram-negative, spiral-shaped microaerophilic pathogen closely associated with gastric and extra-gastric diseases $\mathrm{Hu}$ et al. [1]. Appropriately half of the global population is infected with H. pylori, and the prevalence of $H$. pylori varied among regions, which appeared to be explained by the differences in economic and social conditions Hooi \& Zamani et al. [2,3]. It is now widely accepted that H.pylori is the etiological agent in numerous gastrointestinal (GI) disorders, including dyspepsia, duodenal and gastric ulcer, gastric cancer and mucosa-associated lymphoid tissue (MALT) lymphoma Laheij \& Chunder et al. [1,4,5]. Following colonization of the gastric mucosa, H. pylori induce an inflammatory reaction with neutrophilic gastritis that ultimately results in the clinical manifestation of the infection Go \& Crowe [6]. Currently, there several methods for detecting the presence of HP infection, some are invasive (i.e. require endoscopic biopsy) and others are noninvasive. Histologic evaluation El-Zimaity \& Graham [7], culture Perez-Perez [8], polymerase chain reaction Bravos \& Gilman [9], and rapid urease tests Midolo \& Marshall [10] are typically performed on tissue obtained at endoscopy. Simple non-invasive tests include urea breath tests Vaira \& Vakil [11], serology Cutler et al. [12], and stool antigen testing Monteiro et al. [13]. A review of 22 studies showed that HP stool antigen test had a pretreatment sensitivity of $94 \%$ and specificity of $97 \%$ and a post treatment sensitivity of $93 \%$ and specificity of $96 \%$ Gisbert \& Gisbert et al. $[14,15]$. Determining the optimum treatment of HP infection is difficult because the organism lives in an environment not easily accessible to many medications and because emerging bacterial resistance presents an added challenge. The choice of therapy should consider effectiveness, cost of various regimens and 
side effects. Conventional HP treatment involves multiple drug short-course regimens of antisecretory agents and antibiotics. Despite effective eradication therapies, permanent cure is not always possible where re-infection from environmental sources is highly common Sullivan et al. [16]. Due to the high level of adverse effects associated with the antimicrobials commonly employed in the eradication of HP and the increasing incidence of antimicrobial resistance, much interest has been generated in the development of newer HP eradication modalities. Herbal medicines have been used traditionally for the treatment of a wide range of gastrointestinal disorders including dyspepsia, gastritis and peptic ulcer disease Borrelli \& Thompson $[17,18]$.

Curcumin is a key hydrophobic polyphenolic yellow pigment isolated from turmeric rhizome Curcuma longa Linn, Cai et al. [19]. Turmeric mainly contains three curcuminoids (curcumin, demethocycurcumin, and bisdemethoxycurcumin) and volatile oil Basnet \& Hamidpour et al. [20,21]. Curcumin has anti-oxidant, anti-inflammatory, anticarcinogenic and anti-microbial properties Anand \& Cai et al. [19,22]. Moreover Chemotherapeutic, chemopreventive Sharma et al, [23], hepatoprotective, nephroprotective, thrombosis suppressing, hypoglycemic and antirheumatic effects of curcumin are also well-established Anand et al. [22]. Studies showed that curcumin can cause a high rate of $H$. pylori eradication and gastroprotective effects in mice De et al. [24]. In vitro studies have shown the effectiveness of curcumin extracts against $H$. pylori De et al. [24], Sarkar et al. [25], Vetvicka et al. [26], Ranjbar \& Mohammadi [27].

Mangiferin is a polyphenol (xanthonoid) commonly found in the bark, fruits, and leaves of Mangiferin indica L and in the roots of Salacia chinensis Lv et al. [28]. Mangiferin has a broad spectrum of pharmaceutical activities such as antioxidant, antiinflammation, anti-microbial, anti-invasive, anti-tumor Wauthoz, Singh \& Anand et al. [29-31]. Enormous studies had indicated that mangiferin might act as an anti-carcinogen in various cancer cell line model attributing to its antioxidant, anti-inflammatory, anti-proliferative (cytotoxic), anti-adhesive, and pro-poptotic effect du Plessis-Stoman \& Rajendran et al. [32,33]. Moreover, the gastroprotective activity of mangiferin was reported in an animal model Carvalho et al. [34]. In vitro studies have shown the effectiveness of mangiferin extracts against many bacteria including H. pylori Doughari, Sanrawal \& Zhang [35-37].

In this work, curcumin and mangiferin preparations were assessed clinically for their HP-eradicating efficacy as components of dual or triple omeprazole-based regimens in patients with functional dyspepsia.

\section{Patients and Methods}

\section{Study design}

Sixty H.pylori-positive patients (48 men, 12 women) aged 20 to 56 years with functional dyspepsia, were enrolled in this randomized open-label efficacy study. The study protocol was approved by the Ethics Committee at Al-Amal Specialized Hospital, Cairo, Egypt. Signed written informed consents were obtained from all patients participating in the study. All patients were subjected to detailed history taking (stressing the onset and duration of dyspepstic symptoms), clinical examination and routine laboratory investigations. Functional (non-ulcer) dyspepsia was diagnosed according to the Rome III criteria for functional gastrointestinal disorders Chunder [5]. Patients were randomized to 3 groups, 20 patient each. The first group received Curcumin (400 mg capsule twice daily) plus omeprazole (20 mg twice daily). The second group was treated with mangiferin (200 mg capsule mg capsule twice daily) plus omeprazole $(20 \mathrm{mg}$ twice daily). The third group received a combination of curcumin (400 mg capsule twice daily), mangiferin (200 mg capsule twice daily) and omeprazole (20 mg twice daily). All treatments were given for 14 days. H. Pylori status was determined by the noninvasive stool antigen test Vaira \& Vaira et al. [38,39], before and 4 weeks after eradication therapy Burette [40]. To ensure better patient adherence, the study medications were refilled freely on a weekly basis. During the treatment period, patient education, counselling and clinic visits were planned weekly. Symptom review, medication use and adverse reactions were recorded in each visit.

\section{Setting}

Out-patient treatment at Al-Amal Specialized Hospital Internal Medicine Clinic, Cairo, Egypt.

\section{Inclusion criteria}

Helicobacter pylori-positive dyspeptic patients fulfilling the Rome III diagnostic criteria for functional dyspepsia. According to Rome III criteria, functional dyspepsia is diagnosed when; one or more of the following symptoms are present for at least three months, with onset occurring at least six months before: a) early satiation; b) bothersome postprandial fullness; c) epigastric burning; d) epigastric pain; and e) no evidence of structural disease that is likely to explain the symptoms.

\section{Exclusion criteria}

Patients with history of peptic ulcer disease, gastrooesophageal reflux disease (GORD) or irritable bowel syndrome (IBS), previous treatment with proton pump inhibitors in the preceding 2 weeks of eradication therapy or previous treatment with any antimicrobial agent in the preceding 4 weeks of eradication therapy.

\section{Study drugs}

Curcumin 400 mg capsules (contains 100mg curcuminoids), Pharma Nord, (UK) Ltd.

Mangiferin 200 mg capsules (Mango leaf extract containing $60 \%$ mangiferin), Green Dragon Botanicals, Brattleboro, Vermont, USA. 
Omeprazole 20 mg (Losec®), AstraZeneca.

\section{Helicobacter pylori testing}

Helicobacter pylori status was tested before and 4 weeks after eradication therapy using Helicobacter Pylori Stool Antigen (HpSA), Test Kit, Code \# 53850, Focus Diagnostics, Cypress, California 90630 USA. The principle of the test depends on an immunochromatographic assay that uses antibody- coated colloidal gold to detect the presence of $H$. pylori antigens in stool specimens. The test detects directly antigens in specimens for an active infection. The test is simple and easy to perform and the test results can be visually interpreted within 15 minutes.

\section{Patient education}

Patient education and counselling was performed at the start and on weekly-basis throughout the study. Patients were educated and reassured on the meaning of the symptoms and their benign nature and encouraged to take responsibility for their own health care. Patients were advised of the following lifestyle and dietary modifications:

a) Avoid high-fat meals, alcohol and caffeinated drinks.

b) Eat frequent, but smaller meals, throughout the day and avoid late evening meals

c) Smoking cessation and weight reduction

d) Adopt relaxation and stress management techniques

e) Avoid foods that trigger or worsen the dyspeptic symptoms such as onions, coffee, peppers, citrus fruits, spices and carbonated beverages.

f) Review of current medication for possible cause of dyspepsia.

\section{Efficacy measures}

Primary efficacy measures depend on finding out HPeradication rates (\%) observed for each therapeutic regimen following 14-day therapy using Helicobacter Pylori Stool Antigen (HpSA), Test. Secondary efficacy measures involve monitoring improvements in the severity and frequency of dyspeptic symptoms.

\section{Safety measures}

Safety was assessed by monitoring the incidence of adverse drug reactions (ADRs) and clinical examination. Clinical examination and ADRs were evaluated at weekly intervals.

\section{Data analysis}

Helicobacter pylori eradication rates (\%) were compared using Fisher's exact test (Joosse SA., 2011, available from http:// in-silico.net/statistics/fisher_exact_test). The level of significance was set at $\mathrm{p} \leq 0.05$.

\section{Results}

\section{Efficacy measures}

The H. pylori eradication rates following 14-day therapy were $60 \%$ with mangiferin plus omeprazole, $70 \%$ with curcumin plus omeprazole and $90 \%$ when both curcumin and mangiferin were used in combination with omeprazole. Results are presented in Table 1. As shown in Figure 1, significantly higher eradication rates were obtained with triple curcumin/mangiferin/ omeprazole regimen compared to dual curcumin/omeprazole and dual mangiferin/omeprazole regimens (90\% versus $60 \%$ and $50 \%$, Fisher's exact test, $\mathrm{p} \leq 0.05$ ). The severity, duration and frequency of dyspeptic symptoms were dramatically reduced within hours following initiation of therapy, especially with the triple eradication regimen.

Table 1: $H$ pylori eradication rates with three different herbal omprazole-based regimens.

\begin{tabular}{|c|c|c|}
\hline Regimen & No of Patients & H. pylori Eradication Rates (\%) \\
\hline Mangiferin/Omeprazole & 20 & 50 \\
\hline Curcumin/Omeprazole & 20 & 60 \\
\hline Curcumin/Mangiferin/Omeprazole & 20 & $90^{*}$ \\
\hline
\end{tabular}

Helicobacter pylori eradication rates following 14-day treatment with three different omeprazole-based regimens. ${ }^{*}$ Significantly different from dual regimens ( $p \leq 0.05$, Fisher's exact test).

\section{Safety measures}

All eradication regimens were well tolerated with slight side effects. The most common side effects observed were nausea, fatigue and headache; all are of mild transient nature.

\section{Discussion}

Helicobacter pylori has been associated with the pathogenesis of antral gastritis, duodenal ulcer, and gastric lymphoma. Eradication of $H$. pylori has been shown to reverse or prevent relapse of these diseases. Conventional $H$. pylori treatment involves multiple drug short-course therapy. Gastric acid supressants such as ranitidine or omeprazole have in-vitro activity against HP De Boer et al. [41]. A proton pump inhibitor (e.g., omeprazole) plus clarithromycin plus either amoxicillin or metronidazole have demonstrated impressive eradication rates ( $>85 \%$ ) when used for 10-14 days Chey \& Stenström et al. $[42,43]$. However, antimicrobials employed in the eradication of H. pylori are not without adverse effects and have growing rates of microbial resistance Rimbara \& Savoldi et al. [44,45], therefore, newer treatment modalities are required. 


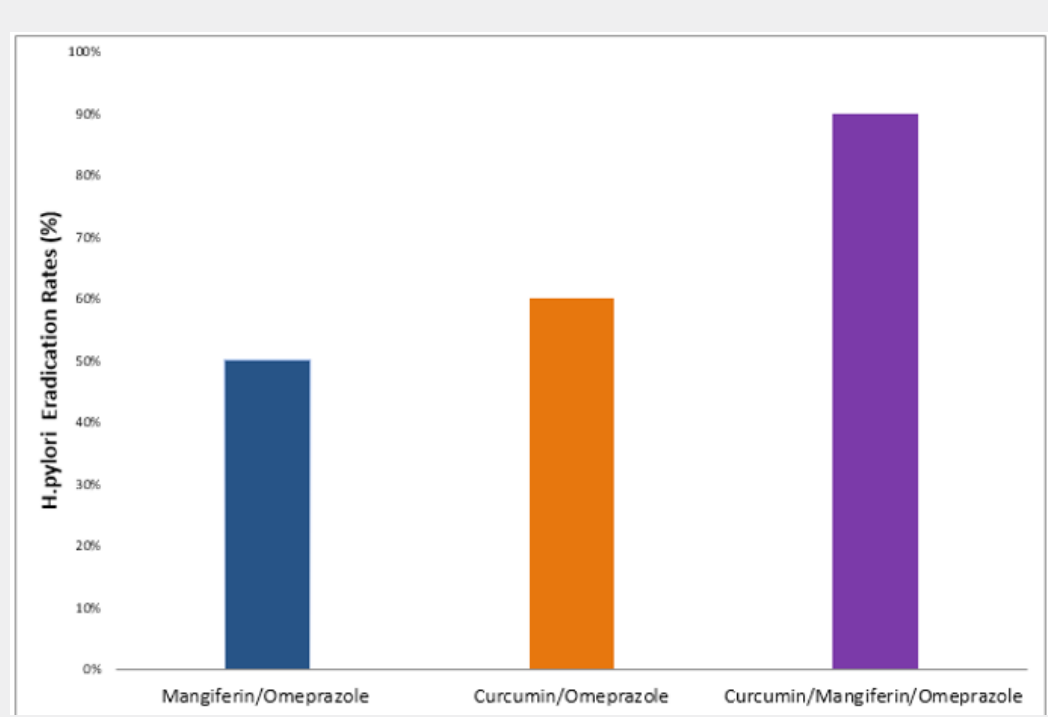

Figure 1: Helicobacter pylori eradication rates following 14-day treatment with three different omeprazole-based regimens. *Significantly different from dual regimens ( $p \leq 0.05$, Fisher's exact test).

The results of the present study revealed that triple curcumin/ mangiferin/omeprazole regimen achieved significantly higher $H$. pylori eradication rates compared to dual curcumin/omeprazole and dual mangiferin/omeprazole regimens in patients with $H$. pylori-associated functional dyspepsia. The H. pylori eradication rate observed with the triple curcumin/mangiferin/omeprazole regimen is comparable to that reported with the conventional anti-H. pylori regimen consisting of omeprazole/clarithromycin plus either amoxicillin or metronidazole. All regimens reduced the severity, duration and frequency of dyspeptic symptoms within few hours following initiation of therapy. The eradication regimens were well tolerated with negligible side effects. The most common side effects observed were nausea, fatigue and headache; all are of mild transient nature. One of the positive outcomes of the study is that the level of patient awareness with their illness was increased as compared to that preceding the study.

Many herbal medicines including curcumin and mangiferin have been used universally as folklore remedies for gastrointestinal disorders. Mangiferin and mango leaves afford gastro protection against gastric injury through the antisecretory and antioxidant mechanisms of action Carvalho \& Neelima et al. [34,46]. Studies suggest that curcumin has a wide range of beneficial properties in many GIT diseases including oral cancer and cancer of the submandibular gland Rai et al. [47], esophageal cancer Hartojo et al. [48] gastric cancer Koo et al. [49], colon cancer Johnson \& Mukhtar [50], inflammatory bowel disease Holt et al. [51], pancreatic cancer Swamy et al. [52], hepatocellular carcinoma Lin et al. [53] and liver fibrosis.

In vitro studies have shown the effectiveness of curcumin extracts against H.pylori De et al. [24], Sarkar et al. [25], Vetvicka et al. [26], Ranjbar \& Mohammadi [27]. All previous studies on curcumin have indicated its bacterial membrane altering properties such as thinning and disruption of the membrane at high concentrations using artificial membranes Anand et al. [54]. Curcumin's anti-H.pylori activity can be attributed to bacterial membrane permeabilizing damage that allows for combined antibiotics to be taken up easily through disrupted bacterial membranes Tyagi et al. [55]. Because of participation of free radicals in the pathogenesis of Helicobacter infection, eliminating these causal inflammatory triggers by the use of curcumin may be a useful strategy. Curcumin can decrease lipid peroxidation (an oxidative damage index) and myeloperoxidase activity through its potent antioxidant activity Menon \& Sudheer [56]. Kali et al, [57] reported that curcumin had an inhibitory effect on biofilmproducing bacteria when used with antibiotics. They also stated that the use of this substance would be beneficial in antibiotic therapy Kali et al. [57]. The results of our study were also in line with the above studies.

In vitro studies have shown the effectiveness of mangiferin extracts against many bacteria including H.pylori Doughari, Sanrawal \& Zhang [35-37]. Vaghasiya et al, [58], reported that ethanolic mango extract containing mangiferin showed potent antibacterial activity against all the clinically isolated bacterial strains and most of the standard bacterial strains which was comparable with that of standard antibiotics Vaghasiya et al, [58]. The anti-H.pylori activity of mangiferin may be related to its antoxidant Agarwala \& Sellamuthu et al. $[59,60]$ and antiinflammatory activity Carvalho \& Morais et al. [34,61].

H. pylori is a known source of free radical production in gastroduodenal disorders Smoot \& Sezikli et al. [62,63]. By virtue of their antioxidant properties, attenuation of the damaging effects of $H$. pylori-generated free radicals on gastrodudenal mucosa 
may contribute to both curcumin' and mangiferin's beneficial effects in eliminating dysepeptic symptoms. Considering the strong link between dyspepsia and H. pylori infections Frigo et al. [64], Laheij et al. [4], inhibition of $H$. pylori by curcumin and mangiferin preparations suggests a plausible mode of action for their therapeutic benefits in dyspepsia and other gastrointestinal disorders [65-69].

\section{Conclusions}

In conclusion, the results of this work demonstrate that curcumin and mangiferin preparations traditionally used for the treatment of gastrointestinal disorders are effective as components of proton pump based- $H$. pylori eradication regimens with little or no adverse reactions. Since $H$. pylori is the causative agent responsible for dyspepsia, gastritis, peptic ulcer disease and gastric carcinoma, might provide newer herbal weapons that can be added to the available antibiotic arsenal. These preparations could furnish a potent anti- $H$. pylori alternative therapy that overcomes the problem of resistance associated with current antibiotic treatment. From the pharmacoeconomic point of view, these herbal preparations provide effective low-cost substitutes to the presently used antibiotics.

\section{Conflict of Interest}

I declare that there is no conflict of interest on this research work. No funds or support were obtained from any source.

\section{Acknowledgements}

I would like to express my deepest appreciation to the Late Dr. Thanaa G. Awad, Consultant Physician for her valuable and kind help.

\section{References}

1. Hu Y, Zhu Y, Lu NH (2020) Recent progress in Helicobacter pylori treatment. Chin Med J 133(3): 335-343.

2. Hooi J, Lai WY, Ng WK, Suen M, Underwood FE, et al. (2017) Global prevalence of Helicobacter pylori infection: systematic review and meta-analysis. Gastroenterology 153(2): 420-429.

3. Zamani M, Ebrahimtabar F, Zamani V, Miller WH, Alizadeh-Navaei R, et al. (2018) Systematic review with meta-analysis: the worldwide prevalence of Helicobacter pylori infection. Aliment Pharmacol Ther 47(7): 868-876.

4. Laheij RJ, Van Rossum LG, Verbeek AL, Jansen JB (2003) Helicobacter pylori infection treatment of nonulcer dyspepsia: an analysis of metaanalyses. J. Clin. Gastroenterol 36(4): 315-320.

5. Chunder R (2011) Non-ulcerative dyspepsia: diagnosis and management. S Afr Pharm J 2: 30-35.

6. Go MF, Crowe SE (2000) Virulence and pathogenicity of Helicobacter pylori. Gastroenterol Clin N Amer 29(3): 649-670.

7. El-Zimaity HM, Graham DY (1999) Evaluation of gastric mucosa biobsy site and number for idetification of Helicobacter pylori or intestinal metaplasia: role of the Sydney System. Hum Path 30(1): 72-77.

8. Perez-Perez GI (2000) Accurate diagnosis of Helicobacter pylori. Culture including transport. Gastroenterol Clin North Am 29(4): 879884 .

9. Bravos ED, Gilman RH (2000) Accurate diagnosis of Helicobacter pylori. Other tests. Gastroenterol Clin North Am 29(4): 925-929.

10. Midolo P, Marshall BJ (2000) Accurate diagnosis of Helicobacter pylori. Urease tests. Gastroenterol Clin North Am 29(4): 871-878.

11. Vaira D, Vakil N (2001) Blood, stool, breath, money and Helicobacter pylori. Gut 48(2): 287-289.

12. Cutler AF, Prasad VM, Santogade P (1998) Four year trends in Helicobacter pylori IgG serology following successful eradication. Am J Med 105(1): 18-20.

13. Monterio L, de Mascarel A, Sarrasqueta AM, Bergey B, Barberis C, et al. (2001) Diagnosis of Helicobacter pylori infection: noninvasive methods compared to invasive methods and evaluation of two new tests. A J Gastroenterol 96(2): 353-358.

14. Gisbert JP, Pajares JM (2001) Diagnosis of Helicobacter pylori infection by stool antigen determination: a systematic review. Am J Gastroenterol 96(10): 2829-2838.

15. Gisbert JP, de la Morena F, Abraira V (2006) Accuracy of monoclonal stool antigen test for the diagnosis of $H$. pylori infection: A systematic review and meta-analysis. Am J Gastroenterol 101(8): 1921-1930.

16. Sullivan PB, Thomas JE, Wight DJ, Neale G, Eastham EJ, et al. (1999) Greenwood B.M. Helicobacter pylori infection in Gambian children with chronic diarrhoea and malnutrition. Arch Dis Child 65: 189-191.

17. Borreli F, Izzo AA (2000) The plant kingdom as a source of antiulcer remedies. Phytother Res 14(8): 581-591.

18. Thompson Coon J, Ernst E (2002) Systemic review: herbal medicinal products for non-ulcer dyspepsia. Aliment Pharmacol Ther 16(10): 1689-1699.

19. Cai XZ, Huang WY, Qiao Y, Du SY, Chen Y, et al. (2013) Inhibitory effects of curcumin on gastric cancer cells: a proteomic study of molecular targets. Phytomedicine 20(6): 495-505.

20. Basnet P, Skalko-Basnet N (2011) Curcumin: an anti-inflammatory molecule from a curry spice on the path to cancer treatment. Molecules 16: $4567-4598$.

21. Hamidpour R, Hamidpour S, Hamidpour M (2015) Turmeric (Curcuma longa): from a variety of traditional medicinal application to its novel roles as active antioxidant, anti-inflammatory, anti-cancer, and antidiabetes. Int J Pharmacol Phytochem Ethnomed 1: 37-45.

22. Anand P, Kunnumakkara AB, Newman RA, Aggarwal BB (2007) Bioavailability of curcumin: problems and promises. Mol Pharm 4(6): 807-818.

23. Sharma RA, Gescher AJ, Steward WP (2005) Curcumin: the story so far. Eur J Cancer 41(13): 1955-1968.

24. De R, Kundu P, Swarnakar S, Ramamurthy T, Chowdhury A, et al. (2009) Antimicrobial activity of curcumin against Helicobacter pylori isolates from India and during infections in mice. Antimicrob Agents Chemother 53: 1592-1597.

25. Sarkar A, De R, Mukhopadhyay AK (2016) Curcumin as a potential therapeutic candidate for Helicobacter pylori associated diseases. World J Gastroenterol 22(9): 2736-2748. 
26. Vetvicka V, Vetvickova J, Fernandez-Botran R (2016) Effects of curcumin on Helicobacter pylori infection. Ann Transl Med 4(24): 479.

27. Ranjbar R, Mohammadi A (2018) Synergistic effects of combined curcumin and antibiotic in ameliorating an animal model of Helicobacter pylori infection. Biomedical Research 29(8): 1702-1707.

28. Lv X L, Wang Y, Hu B, Kang L, Xin J (2016) Neurotherapeutic effect of mangiferin against hypoxic-ischemic encephalopathy in neonatal rats. Afr. J Tradit Complement Altern Med 13(2): 229-236.

29. Wauthoz N, Balde A, Balde ES, Van Damme M, Duez P (2007) Ethnopharmacology of Mangifera indica L. bark and pharmacological studies of its main C-glucosylxanthone, mangiferin. Int J Biomed Pharma Sci 1(2): 112-119.

30. Singh SK, Tiwari R M, Sinha SK, Danta CC, Prasad SK (2012) Antimicrobial evaluation of mangiferin and its synthesized analogues. Asian Pac J Trop Biomed 2(2): S884-887.

31. Anand G, Ravinanthan M, Basaviah R, Shetty AV (2015) In vitro antimicrobial and cytotoxic effects of Anacardium occidentale and Mangifera indica in oral care. J Pharm Bioall Sci 7(1): 69-74.

32. du Plessis-Stoman D, du Preez JGH, Van de Venter M (2011) Combination treatment with oxaliplatin and mangiferin causes increased apoptosis and downregulation of NFKB in cancer cell lines. Afr J Tradit Complement Altern Med 8(2): 177-184.

33. Rajendran P, Rengarajan T, Nandakumar N, Divya H, Nishigaki (2015) Mangiferin in cancer chemoprevention and treatment: pharmacokinetics and molecular targets. J Recept Sig Transd 35(1): 76-84.

34. Carvalho AC, Guedes MM, de Souza AL, Trevisan MT, Lima AF, et al (2007) Gastroprotective effect of mangiferin, a xanthonoid from Mangifera indica, against gastric injury induced by ethanol and indomethacin in rodents. Planta Medica.73(13): 1372-1376.

35. Doughari JH, Manzara S (2008) In vitro antibacterial activity of crude leaf extracts of Mangifera indica Linn. African Journal of Microbiology Research 2: 067-072.

36. Sanrawal Alka, Sushil Kumar (2013) Antibacterial activity of MI leaves against drug-resistant bacterial strain. International journal of advanced research 1(6): 82-86.

37. Zhang Qiu-jie, Lu Yue Lu (2017) Inhibitory activity of mangiferin on Helicobacter pylori-induced inflammation in human gastric carcinoma AGS cells. Afr J Tradit Complement Altern Med 14(1): 263-271.

38. Vaira D, Malfertheiner P, Mergraud F, Axon A.J, Deltenre M, et al. (2000) Noninvasive antigen-based assay for assessing Helicobacter pylori eradication; a European multicenter study. The European Helicobacter pylori HpSA study group. Am J Gastroenterol 95(4): 925-229.

39. Vaira D, Vakil N, Menegatti M, Van't Hoff B, Ricci C, et al. (2002) The stool antigen test for detection of Helicobacter pylori after eradication therapy. Ann Intern Med 136(4): 280-287.

40. Burette A (1998) How and when to test or retest for H. pylori. Acta Gastro-Enterologica Belgica 61(3): 336-343.

41. De Boer W.A, Driessen W, Jansz A, Tytgat G (1995) Effect of acid suppression on efficacy of treatment for Helicobacter pylori infection. Lancet 345(8953): 817-820.

42. Chey WD, Wong BC (2007) American College of Gastroenterology guidelines on the management of Helicobacter pylori infection. Am J Gastroenterol 102: 1808-1825.

43. Stenström B, Mendis A, Marshall B (2008) Helicobacter pylori. The latest in diagnosis and treatment. Aust Fam Physician 37(8): 608-612.

44. Rimbara E, Fischbach L, Graham DY (2011) Optimal therapy for
Helicobacter pylori infections. Nat Rev Gastroenterol Hepatol 8(2): 7988.

45. Savoldi A, Carrara E, Graham DY, Conti M, Tacconelli E (2018) Prevalence of antibiotic resistance in Helicobacter pylori: a systematic review and meta-analysis in World Health Organization Regions. Gastroenterology 155(5): 1372-1382.

46. Neelima N, Sudhakar M, Patil MB, Lakshmi BWS (2012) Antiulcer Activity and HPTLC Analysis of Mangifera indica L. Leaves. International Journal of Pharmaceutical and Phytopharmacology Research 1(4): 146-155.

47. Rai B, Kaur J, Jacobs R, Singh J (2010) Possible action mechanism for curcumin in pre-cancerous lesions based on serum and salivary markers of oxidative stress. J Oral Sci 52(2): 251-256.

48. Hartojo W, Silvers AL, Thomas DG, Seder CW, Lin L, et al. (2010) Curcumin promotes apoptosis, increases chemosensitivity, and inhibits nuclear factor kappaB in esophageal adenocarcinoma. Transl Oncol 3(2): 99-108.

49. Koo JY, Kim HJ, Jung KO, Park KY (2004) Curcumin inhibits the growth of AGS human gastric carcinoma cells in vitro and shows synergism with 5-fluorouracil. J Med Food 7(2): 117-121

50. Johnson JJ, Mukhtar H (2007) Curcumin for chemoprevention of colon cancer. Cancer Lett 255(2): 170-181.

51. Holt PR, Katz S, Kirshoff R (2005) Curcumin therapy in inflammatory bowel disease: a pilot study. Dig Dis Sci 50(11): 2191-2193.

52. Swamy MV, Citineni B, Patlolla JM, Mohammed A, Zhang Y, et al (2008) Prevention and treatment of pancreatic cancer by curcumin in combination with omega-3 fatty acids. Nutr Cancer 60(Suppl 1): 81-89

53. Lin LI, Ke YF, Ko YC, Lin JK (1998) Curcumin inhibits SK-Hep-1 hepatocellular carcinoma cell invasion in vitro and suppresses matrix metalloproteinase-9 secretion. Oncology 55(4): 349-353.

54. Anand P, Nair HB, Sung B, Kannumakkara AB, Yadav VR, et al. (2010) Design of curcumin loaded PLGA nanoparticles formulation with enhanced cellular uptake, and increased bioactivity in vitro and superior bioavailability in vivo. Biochem Pharmacol 79(3): 330-338.

55. Tyagi P, Singh M, Kumari H, Kumari A, Mukhopadhyay K (2015) Bactericidal activity of curcumin I is associated with damaging of bacterial membrane. PLoS ONE 10(3): e0121313.

56. Menon VP, Sudheer AR (2007) Antioxidant and anti-inflammatory properties of curcumin. Adv Exp Med Biol 595: 105-125.

57. Kali A, Bhuvaneshwar D, Charles PM, Seetha KS (2016) Antibacterial synergy of curcumin with antibiotics against biofilm producing clinical bacterial isolates. J Basic Clin Pharma 7(3): 93-96.

58. Vaghasiva Y, Patel H, Chanda S (2011) Antibacterial activity of Mangifera indica L. seeds against some human pathogenic bacterial strains. Afr. J. Biotechnol 10(70): 15788-15794.

59. Agarwala S, NR B, Mudholkar K, Bhuwania R, Satish Rao BS (2012) Mangiferin, a dietary xanthone protects against mercury-induced toxicity in HepG2 cells. Environ Toxicol 27(2): 117-127.

60. Sellamuthu PS, Arulselvan P, Muniappan BP, Fakurazi S, Kandasamy M (2013) Mangiferin from Salacia chinensis prevents oxidative stress and protects pancreatic $\beta$-cells in streptozotocin-induced diabetic rats. J Med Food 16(8): 719-727.

61. Morais TC, Arruda BR, de Sousa MH, Trevisan MT, de Araújo VD, et al. (2015) Mangiferin ameliorates the intestinal inflammatory response and the impaired gastrointestinal motility in mouse model of postoperative ileus. Naunyn Schmiedebergs Arch Pharmacol 388(5): 531-538. 
62. Smoot DT, Elliott TB, Verspaget HW, Jones D, Allen CR (2000) Influence of Helicobacter pylori on reactive oxygen-induced gastric epithelial cell injury. Carcinogenesis 21(11): 2091-2095.

63. Sezikli M, Cetinkaya ZA, Sezikli H, Guzelbulut F, Tiftikci A, et al. (2009) Oxidative stress in Helicobacter pylori infection: does supplementation with vitamins $\mathrm{C}$ and $\mathrm{E}$ increase the eradication rate? Helicobacter 14(4): 280-285.

64. Frigo P, Lang C, Reisenberger K, Kolbl H, Hirschl AM (1998) Hyperemesis gravidarum associated with Helicobacter pylori seropositvity. Obstet. Gynecol 91(4): 615-617.

65. Ali S.M, Khan A, Ahmed I, Musaddiq M, Ahmed K, et al. (2005) Antimicrobial activities of Eugenol and Cinnamaldehyde against the human gastric pathogen Helicobacter pylori. Ann Clin Microbiol Antimicrob 4(1): 20.

66. Blumenthal M (1988) The complete German Commission E Monographs - Therapeutic Guide to Herbal Medicines. The American Botanical Council 1988; Austin, TX, USA.

67. Cutler AF, Prasad VM, Santogade P (1998) Four-year trends in Helicobacter pylori IgG serology following successful eradication. Am J Med 105(1): 18-20.

68. Shan B, Cai Y, Sun M, Corke H (2005) Antioxidant capacity of 26 spice extracts and characterization of their phenolic constituents. J Agric Food Chem 53(20): 7749-7759.

This work is licensed under Creative Commons Attribution 4.0 License DOI:10.19080/ARGH.2020.15.555906 